\title{
RISK PROFILE AND HEMODYNAMIC CHARACTERISTICS IN YOUNG SUBJECTS WITH HIGH NORMAL ARTERIAL BLOOD PRESSURE
}

\author{
Julia Nikolova ${ }^{1}$, Mariana Bacelova ${ }^{1}$, Petar Hrischev ${ }^{1}$, Margarita Hadjieva ${ }^{1}$, Petar Nikolov ${ }^{3}$, \\ Daniela Koleva ${ }^{2}$ \\ ${ }^{1}$ Department of Physiology, Medical Faculty, Medical University - Plovdiv, \\ ${ }^{2}$ Second Department of Internal Diseases - Section of Endocrinology, Medical Faculty, \\ Medical University - Plovdiv, ${ }^{3}$ First Department of Internal Diseases - Section Cardiology, \\ Medical Faculty, Medical University - Plovdiv
}

\begin{abstract}
INTRODUCTION: The European Society of Cardiology classifies arterial pressure bellow $140 / 90 \mathrm{mmHg}$ as optimal(below 120/80 $\mathrm{mmHg}$ ), normal (120-129 $\mathrm{mmHg}$ for systolic and/or 80-84 $\mathrm{mmHg}$ for diastolic) and high normal (130-139 mmHg for systolic and/or 85-89 mmHg for diastolic). The argument is concerned with different cardiovascular risk. The possibility of arterial hypertension $(\mathrm{AH})$ to appear is higher in individuals with high normal arterial pressure (HNAP). Such individuals could be treated with non-drug therapy as the idea is the appearance of $\mathrm{AH}$ to be delayed and the cardiovascular risk to be reduced. The aim of the study was the risk and hemodynamic profile of the students of medicine with HNAP to be examined.

MATERIAL AND METHODS: The object of the investigation is focused on students of medicine with HNAP. The two followed-up groups - with HNAP and with optimal arterial blood pressure (OBP) assumed this pattern on the base of inquiry and screening among 116 students (60 men and 56 women). Inquiry and anthropometric methods, arterial pressure monitoring and impedance cardiography were carried up.

RESULTS: The dominance of some factors, predisposing hypertension appearance as overweight, increased salt consumption, family history was registered in HNAP group. Hemodynamic evaluation manifested hyperkinetic type of circulation.

CONCLUSION: Medical students' risk and hemodynamic profile within HNAP group is close to that of the hypertensive individuals. That makes them a special risk group and there is a necessity of non-drug therapy means application in order for $\mathrm{AH}$ expression to be delayed.
\end{abstract}

Keywords: high normal AP, risk factors, impedance cardiography

Address for correspondence:

Julia Nikolova

Medical University - Plovdiv

$15 A$ Vasil Aprilov blvd.

4002 Plovdiv, Bulgaria

e-mail:junikol@yahoo.com

Received: August 4, 2015

Accepted: September 3, 2015

\section{INTRODUCTION}

The arterial blood pressure (AP) is an integral index reflecting the functional state of the cardiovascular system. Instead of it being a dynamic parameter with short- term and circadian deviations, it is maintained in definite referent values. The argument of the European Society of Cardiology (ESC) to define AP values under $140 / 90 \mathrm{mmHg}$ in three catego- 
ries - optimal (under 120/80 $\mathrm{mmHg}$ ), normal (120$129 \mathrm{mmHg}$ for systolic and/or $80-84 \mathrm{mmHg}$ for diastolic) and high normal (130-139 $\mathrm{mmHg}$ for systolic and/or 85-89 $\mathrm{mmHg}$ for diastolic) is connected to the different cardiovascular risks $(1,2)$. The risk of arterial hypertension $(\mathrm{AH})$ to develop is higher in individuals with high normal AP (HNAP) $(3,4,5,6,7,8)$.

The individuals with HNAP are of interest because of the possibility of them to be treated by a non-drug therapy and thus delaying the $\mathrm{AH}$ appearance and reducing the cardiovascular risk. Students of medicine are a special group, taking into consideration their non-dynamics and proclivity for obesity, predisposing thus to $\mathrm{AH}$.

The objective of the study is for the risky profile and some haemodynamic indices in the students of medicine to be followed.

\section{MATERIAL AND METHODS}

Screening of AP, measured by Microlife, Switzerland device, was carried out among 116 students of medicine at the age of $23 \pm 1.3$ years ( 60 men and 56 women). Two groups were formed: with HNAP $(\mathrm{n}=23: 12$ men and 11 women; 19,8\%) and controls with optimal AP (OAP, n=28: 14 men and 14 women; $24,1 \%)$.

Inquiry method: Family history, reduced physical activity, dietary habits leading to the appearance of $\mathrm{AH}$ and smoking as a separate risk factor for cardiovascular diseases were registered.

Anthropometric examination, carried out by the TANITA BC-420 device. Body Mass Index (BMI) standard index for obesity assessment was a followup. It is calculated as the body mass in kilograms is divided by the height in square meters, BMI $=\mathrm{kg} / \mathrm{m}^{2}$ $(9,10,11)$. The percentages of fat and water were calculated too.
Monitoring of AP and heart rate (HR) by CNAP ${ }^{\infty}$ "HD" (Biopac Instruments, USA). The systolic, diastolic, mean AP and heart rate were followed within 15 minutes after rest at night and 15 minutes at rest. The device consists of two cuffs - single and double. The single, i.e. standard one is placed on the arm, while the double one - on the hand's fingers. $\mathrm{CNAP}^{\circ}$ "HD" (Biopac Instruments, USA) works using the method of „vessel emptying” based on the Penaz' principle $(12,13,14)$. The pressure outside, carried by the finger cuffs could be changed thus maintaining constant blood volume within the fingers (the vessel is clamped by a constant diameter). The fingers' blood volume is measured by an infrared sensor. The change of the vasomotor tone to each heart beat is corrected by a rapid analysis of the pulse wave, giving precise AP measurement of up to $\pm 5 \mathrm{mmHg}(6 \mathrm{kPa})$.

Impedance cardiography (ICG), carried out by NICO100C (Biopac Instruments, USA). ICG is based on electrical voltage changes registered in the thoracic region (due to changes in the volume of ejected blood within the systole) when an alternating current with fixed frequency and amplitude is conducted $(15,16,17,18,19,20,21,22)$. Seventeen hemodynamic indices are followed up by ICG and are reflected in details in table 5 .

The statistical processing was carried out by SPSS 16 package - descriptive analysis and paired t-test.

\section{RESULTS}

The inquiry data (Table 1) show AH risk factors dominance in the HNAP group. The percentage of smoking in this group is $61.5 \%$, while in the OAP group it is $38.5 \%$. Almost doubled is the percentage of increased consumption of salt - 79\% in HNAP individuals, compared to that in the controls - $43 \%$.

Table 1. Inquiry data in HNAP and OAP groups

\begin{tabular}{|l|c|c|c|}
\hline \multicolumn{1}{c|}{ GROUPS } & HNAP & OAP & P \\
RISK & & $38.5 \%$ & $\mathrm{p}<0.05$ \\
FACTORS & $61.5 \%$ & $14 \%$ & $\mathrm{NS}$ \\
\hline Tobacco smoking - 10 cigars mean per day & $17 \%$ & $43 \%$ & $\mathrm{p}<0.05$ \\
Family history for arterial hypertension & $79 \%$ & $49 \%$ & $\mathrm{p}<0.05$ \\
Increased consumption of salt & $71 \%$ & & \\
Reduced physical activity & & & \\
\hline
\end{tabular}


Julia Nikolova, Mariana Bacelova, Petar Hrischev et al.

The physical activity is almost twice as low in the students with HNAP - 71\% to $49 \%$ in OAP individuals. The family history for $\mathrm{AH}$ is of a higher percentage (17\%), compared to the controls (14\%).

The results from the anthropometric examination show that there is no significant difference between both groups regarding IBM and the percentage of body fats and water (Table 2). sented on Table 4. Significantly higher $(91.41 \pm 10.64)$ and shorter $(0.26 \pm 0.03)$ are the heart rate and the mechanic systole duration in HNAP students in comparison to OAP, $70.53 \pm 10.91$ and $0.29 \pm 0.02$, respectively. Velocity indices and vascular resistance show tendency to be increased and the stroke volume to be decreased in HNAP individuals.

Table 2. Anthropometric indices, measured by TANITA BC-420 devise in HNAP and OAP groups

\begin{tabular}{lc|cc|} 
& GROUPS & $\begin{array}{c}\text { OAP } \\
\text { Mean } \pm \text { SD }\end{array}$ & $\begin{array}{c}\text { HNAP } \\
\text { Mean } \pm \text { SD }\end{array}$ \\
INDICES & & & P \\
BMI $\left(\mathrm{kg} / \mathrm{m}^{2}\right)$ & $23.10 \pm 2.58$ & $23.06 \pm 2.28$ & $>0.05$ \\
men & $19.72 \pm 2.49$ & $20.92 \pm 1.80$ & $>0.05$ \\
women & & & $>0.05$ \\
\% FATS & $15.88 \pm 7.4$ & $14.38 \pm 4.35$ & $>0.05$ \\
men & $17.89 \pm 8.43$ & $21.76 \pm 5.69$ & $>0.05$ \\
women & & & $>0.05$ \\
men WATER & $58.72 \pm 5.07$ & $58.34 \pm 4.93$ & $54.64 \pm 3.47$ \\
women & $51.03 \pm 14.58$ & & \\
\hline \hline
\end{tabular}

BMI - body mass index

The AP monitoring data reflect into details the systolic, diastolic and pulse AP values and HR values in both groups (Table 3).

\section{DISCUSSION}

The AP values under 140/90 $\mathrm{mmHg}$ are not a

Table 3. Arterial pressure (AP) and heart rate (HR) values in HNAP and OAP groups

\begin{tabular}{|c|c|c|c|}
\hline GROUPS & $\begin{array}{c}\text { HNAP } \\
\text { Mean } \pm \text { SD } \\
\mathbf{N}=\mathbf{2 3}\end{array}$ & $\begin{array}{c}\text { OAP } \\
\text { Mean } \pm \text { SD } \\
\mathbf{N}=\mathbf{2 8}\end{array}$ & $\mathbf{P}$ \\
\hline S P (mmHg) & $132.84 \pm 4.7$ & $115.76 \pm 3.7$ & $<0.01^{\star}$ \\
\hline D P (mmHg) & $86.44 \pm 2.5$ & $72.80 \pm 6.24$ & $<0.01^{\star}$ \\
\hline H R (imp/min) & $93.7 \pm 16.4$ & $70.7 \pm 11$ & $<0.01^{\star}$ \\
\hline P P (mmHg) & $46.4 \pm 2.2$ & $42.96 \pm 4.35$ & $<0.01^{\star}$ \\
\hline
\end{tabular}

$S P$ - systolic pressure, DP- diastolic pressure, PP - pulse pressure, HR - heart rate, NHAP - high normal arterial pressure group; OAP - optimal arterial pressure group

The monitoring indices mean values of the blood flow, peripheral vascular resistance and contractility thoracic flow content registered by ICG are repre- homogenic category. It is often divided by ESC into tree sub categories - optimal, normal and high normal $(1,2)$. The students of medicine are an object of investigation due to the stress and the possible re- 
Risk profile and hemodynamic characteristics in young subjects with high normal arterial blood pressure

Table 4. Hemodynamic indices, registered by ICG in HNAP and OAP groups

\begin{tabular}{|c|c|c|c|}
\hline GROUPS & $\begin{array}{c}\text { OAP } \\
\text { Mean } \pm \text { SD }\end{array}$ & $\begin{array}{c}\text { HNAP } \\
\text { Mean } \pm \text { SD }\end{array}$ & $\mathrm{P}$ \\
\hline Heart rate, $\mathbf{H R}(\mathrm{imp} / \mathrm{s})$ & $70.53 \pm 10.91$ & $91.41 \pm 10.64$ & $<0.01^{\star}$ \\
\hline Thoracic fluid content, TFC $(1 / \Omega)$ & $0.033 \pm 0.01$ & $0.033 \pm 0.01$ & $>0.05$ \\
\hline Velocity index, VI (1/s) & $0.05 \pm 0.04$ & $0.06 \pm 0.03$ & $>0.05$ \\
\hline Pre-ejection period, $\mathbf{P E P}(\mathbf{s})$ & $0.13 \pm 0.02$ & $0.12 \pm 0.01$ & $>0.05$ \\
\hline Left ventricular ejection time, $\mathbf{L V E T}(\mathbf{s})$ & $0.29 \pm 0.02$ & $0.26 \pm 0.03$ & $<0.05^{\star}$ \\
\hline Stroke volume, SV(mL/beat) & $104.75 \pm 56$ & $79.08 \pm 24.81$ & $>0.05$ \\
\hline Stroke index, SI (mL/beat) $/ \mathbf{m}^{2}$ & $54 \pm 33.9$ & $42 \pm 13.61$ & $>0.05$ \\
\hline SV / SI & $1.99 \pm 0.19$ & $1.88 \pm 0.09$ & $>0.05$ \\
\hline Cardiac output, $\mathrm{CO}(\mathrm{L} / \mathrm{min})$ & $6.9 \pm 2.48$ & $7.1 \pm 3.18$ & $>0.05$ \\
\hline Cardiac index, $\mathrm{CI}(\mathrm{L} / \mathrm{min}) / \mathrm{m}^{2}$ & $3.5 \pm 1.57$ & $3.8 \pm 1.79$ & $>0.05$ \\
\hline $\mathrm{CO} / \mathrm{CI}$ & $1.99 \pm 0.18$ & $1.9 \pm \mathbf{0 . 1 4}$ & $>0.05$ \\
\hline Systemic vascular resistance, $\mathbf{S V R}$ (dynes/s/ $\mathbf{c m}^{-5}$ ) & $1017.87 \pm 283.29$ & $1194 \pm 386.29$ & $>0.05$ \\
\hline Systemic vascular resistance index, SVRI (dynes.s. $\mathbf{c m}^{2} . \mathbf{c m}^{-5}$ ) & $2032.5 \pm 578.69$ & $2265.6 \pm 675.96$ & $>0.05$ \\
\hline Acceleration index, $\operatorname{ACI}\left(1 / \mathbf{s}^{2}\right)$ & $0.97 \pm 0.64$ & $0.9 \pm 0.54$ & $>0.05$ \\
\hline Left cardiac work, LCW(kg.m) & $6.98 \pm 2.50$ & $7.15 \pm 3.20$ & $>0.05$ \\
\hline Left cardiac work index, LCWI (gm.m/m²) & $3.57 \pm 1.57$ & $3.78 \pm 1.80$ & $>0.05$ \\
\hline Systiolic time ratio, STR & $0.43 \pm 0.05$ & $0.60 \pm 0.36$ & $>0.05$ \\
\hline
\end{tabular}

HNAP - high normal arterial pressure group; OAP - optimal arterial pressure group.

The Stroke volume is calculated by Sramek-Bernstein formule (22)

duced physical activity they undergo. The percentage of HNAP individuals is comparatively high (19.8\%). As reasons there could be pointed predisposing factors such as increased consumption of salt, overweight, reduced physical activity. Higher percentage of family history for $\mathrm{AH}$ is present in this group too. It seems that the risk profile in hypertensives as in HNAP individuals is one and the same. In regard to this, the risk profile correction in HNAP objects will prevent the AH appearance $(3,4,7,8,23,24,25,26,27,2$ 8,29 ).

As far as the hemodynamic assessment is concerned, the deviations in the HNAP group are similar to that seen in the first stage of $\mathrm{AH}$ - hyperkinetic type of circulation. Increased HR and shortened duration of left ventricular ejection are registered too. This implies that the increased sympathetic tone, being a basis for the hyperkinetic model, is present in the HNAP students. Sympathetic tone dominance coupled with family pre-disposition is the leading factor in $\mathrm{AH}$ pathogenesis $(29,30,31)$.

\section{CONCLUSION}

The risk factors for HNAP are the same as those for AP. The hemodynamic profile of HNAP students of medicine indicates increased cardiac frequency and shortened duration for the left ventricular ejection and could be connected to increased sympathetic nerve activity.

As far as the HNAP individuals' therapeutic plan is concerned, the recommendation is directed to risk profile correction - reduction of body weight, consumption of salt, no smoking. The increased physical activity could regulate the autonomic nerve system disorder and reduce the sympathetic tone activity. The early risk factors correction in students of medicine will delay the appearance of $\mathrm{AH}$ and will reduce the possibility of the appearance of cardiovascular incidents. 
Julia Nikolova, Mariana Bacelova, Petar Hrischev et al.

Table 5. Referent values and nomenclature of ICG indices by literally data

\section{INDEX}

Heart rate, $\mathrm{HR}$ (imp/s)

Thoracic fluid content, TFC $(1 / \Omega)$

Velocity index, $\mathrm{VI}(1 / \mathrm{s})$

Pre-ejection period, $\mathrm{PEP}(\mathrm{s})$

Left ventricular ejection time, LVET(s)

Stroke Volume, SV (mL/beat)

Stroke Index, SI (ml/beat) $/ \mathrm{m}^{2}$

Cardiac output $\mathrm{CO}(\mathrm{L} / \mathrm{min})$

Cardiac index $(\mathrm{CI})(\mathrm{L} / \mathrm{min}) / \mathrm{m}^{2}$

Systemic vascular resistance, SVR (dynes $/ \mathrm{s} / \mathrm{cm}^{-5}$ )

Systemic vascular resistance index, SVRI (dynes.s. $\mathrm{cm}^{2} . \mathrm{cm}^{-5}$ )

Acceleration index, ACI $\left(1 / \mathrm{s}^{2)}\right.$

Left cardiac work, LCW (kg.m)

Systiolic time ratio, STR

\section{REFERENT VALUES}

58-86

$0.021-0.050$

$0.033-0.065$

$0.05-0.12$

$0.25-0.35$

$60-250$

$35-65$

$4-8$

$2.5-4.7$

$742-1378$

$1337-2483$

$0.7-1.7$

$3-5.5$

$0.3-0.5$

\section{REFERENCES}

1. Kaplan, N. Kaplan's Clinical Hypertension - ninth edition, Philadelphia, Lippincott, Williams\&Wilkins, 2006, 11-12.

2. Reappraisal of European guidelines of hypertension management. Journal of Hypertens. 2009; 27(11):2121-2158.

3. Gupta AK, McGlone M, Greenway FL et al. Prehypertension in disease-free adults: a marker for an adverse cardiometabolic risk profile. Hypertens Res. 2010; 33: 905-910

4. Lee M, Saver J, Chang B et al. Presence of baseline prehypertension and risk of incident stroke - a meta-analysis. Neurology. 2011; 77: 1330-1.

5. Conroy RM, Pyörälä K, Fitzgerald AP et al. Estimation of ten-year risk of fatal cardiovascular disease in Europe: the SCORE project. European Heart Journal. 2003; 24: 987-1003.

6. Lifon et al. Molecular mechanism of human hypertension. Cell. 2001; vol 104, issue 4, 545-556.

7. FJ, Mac Gregor GA. A comprehensive review on salt and health and current experience of worldwide salt reduction programmes. J Hum Hypertens. 2009 ; 23(6):363-84.

8. Dickinson HO, Mason JM, Nikolson DJ, Compbell F, BeyerFR, Cook JJ, WilliamsB, Ford GA. Lifestyle interventions to reduce raised blood pressure: a systematic review of randomized controlled trials. Journal Hypertension. 2006; 2015-2033.

9. Gray DS, Fujioka K. Use of relative weight and Body Mass Index for the determination of adiposity. J Clin Epidemiol.1991; 44 (6): 545-50.

10. Berrington de Gonzalez A, Hartge P, Cerhan JR, Flint AJ, Hannan L, MacInnis RJ et al. Body-Mass Index and Mortality among 1.46 Million White Adults. N. Engl. J. Med. 2010; 363 (23): 2211-9.

11. Koleva D, Mitkov M, Orbetsova M. Screening of obesity as a main risk factor for the development of metabolic syndrome.MedInfo.2012;4,7-9. (in Bulgarian)

12. Dueck R, Jameson LC. Reliability of hypotension detection with noninvasive radial artery beat-tobeat versus upper arm cuff BP monitoring. Anesth Analg. 2006; 102 Suppl:S10.

13. Fortin, J, Marte, W, Grüllenberger, R, Hacker, A, Habenbacher, W, Heller, A et al. Continuous non-invasive blood pressure monitoring using concentrically interlocking control loops. Computers in biology and medicine. 2006; 36(9), 941-57.

14. Cybulsky G. Ambulatory Impedance Cardiography: The System and their Applications. 2011.

15. Sanidas EA, Grammatikopoulos $K$, Anastasiadis G, Papadopoulos D, Daskalaki M, Votteas V. Thoracic fluid content and impedance cardiography: a 
novel and promising noninvasive method for assessing the hemodynamic effects of diuretics in hypertensive patients. 2009 Nov-Dec;50(6):465

16. Stevanović $\mathrm{P}$, Šćepanović $\mathrm{R}$, Radovanović $\mathrm{D}$, Bajec D, Perunović R, Stojanović D, Stevanović D. Thoracic electrical bioimpedance theory and clinical possibilities in perioperative medicine . Signa Vitae 2008; 3 Suppl 1: S 22 - 27

17. Van De Water JM, Miller TW, Vogel RL, Mount $\mathrm{BE}$, Dalton ML. Impedance cardiography: the next vital sign technology? Chest. 2003;123:2028-33.

18. Shoemaker WC, Wo CC, Bishop MH, Thangathurai D, Patil RS. Noninvasive hemodynamic monitoring of critical patients in the emergency department. Acad Emerg Med 1996;3:675-81.

19. Humeau A, Steenbergen W, Nilsson H, Strömberg T, (2007) Laser Doppler perfusion monitoring and imaging: novel approaches. Med. Biol. Eng. Comput. 2007;45:421-435.

20. Iliev I, Tabakov S. Multichannel wideband measuring of bio-impedance with logarithmic characteristics. Available from: http://ecad.tu-sofia. bg/et/2000/Statii\%20ET2000-III/Multichanel\%20

Device\%20for\%20Bioimpedance\%20

Measurement\%20with\%20Logarithmic\%20

Characteristic.pdf (in Bulgarian)

21. Petrov G, Tsvetkov P, Iliev P. Non-invasive medical measuring devices. Metrology and metrological provision. Sozopol, 2006. (in Bulgarian)

22. Biopac MP hardware and software manuals.

23. Nikolov F.P. , Nikolov P. ,Nikolova J. Prevalence and Risk Profile of Prehypertension in South Bulgaria. Conference on PreHypertension \& Cardio Metabolic Syndrome ;February 24-27, 2011, Vienna, Austria, PO-51.

24. Vasan RS, Larson MG, Leip EP et al. Impact of high-normal blood pressure on the risk of cardiovascular disease. N EnglJ Med. 2001;345:1291-7.

25. Wang Y, Wang QJ. The prevalence of prehypertension and hypertension among US adults according to the new National Joint Committee Guidelines. Arch. Int. Med. 2004; 164 (19):2126-34.

26. Greenlund KJ, Croft JB, Mensah GA. Prevalence of heart disease and stroke risk factors in persons with pre hypertension in the United States. Arch. Int. Med .2004;164(19):2113-8.
27. Neter JE, Stam BE, Kok FJ, Grobbee DE, Geleijnse JM. Influence of weight reduction on blood pressure: a meta-analysis of randomized controlled trials. Hypertension. 2003; 42:878-884 MA.

28. He FJ, MacGregor GA. How far should salt intake be reduced. Hypertension. 2003; 42:1093-1099 RV.

29. Narkiewicz K, Phillips BG, Kato M et al. A gender selective interaction between aging, blood pressure and sympathetic nerve activity. Hypertension. $2005 ; 45 ; 522-52$.

30. Cornelissen VA, Fagard RH. Effects of endurance training on blood hypertensive patients. Circulation. 2005; 111:1012-1018.

31. Julius S. et al. Sympathetic overactivity in hypertension Am J Hypertens. 1996; 113-120. 